\title{
Heating Season Performance Improvements for a Solar Heat Pipe System
}

8 July 2014

Brian S. Robinson \& M. Keith Sharp 


\begin{abstract}
An improved model of a heat pipe augmented passive solar space heating system was tested. Computer simulations showed that the new model, featuring key design modifications including a copper absorber, thicker insulation, a rubber adiabatic section, and one condenser exposed directly to room air, has significantly improved heat delivery to the room and reduced losses. The new prototype was tested alongside the previous prototype in a two-room passive solar test facility during January through February of 2013. Results showed that modifications implemented for the new model contributed to increased rate of useful thermal gains to thermal storage and to the room, and decreased rate of thermal losses to ambient. Average daily peak efficiencies for the previous system and the new system were $80.7 \%$ and $85.0 \%$, respectively. Furthermore, the average storage temperature for the new model, over the entire testing period, was $13.4 \%$ higher than that of the previous model; while the average room temperature over the same period was $24.6 \%$ greater for the new system. Simulations matched well with experimental data from the new prototype after parametric adjustments were made to the thermal capacitance of the room and conductances between evaporators and condensers, storage tank and room, solar wall insulation, and the load to collector ratio.
\end{abstract}




\section{INTRODUCTION}

The heat pipe augmented solar wall (Fig. 1) is a type of isolated gain passive spaceheating system that significantly outperforms direct and indirect gain systems by taking advantage of the thermal diode effect of heat transfer in heat pipes [Corliss 1979, Susheela \& Sharp 2001, Albanese et al. 2012, Nkwetta et al. 2013, Robinson et al. 2013]. The heat pipe units operate by boiling fluid in the evaporator section connected to a solar absorber and condensing vapor in the condenser section within a thermal storage tank. Two-phase heat transfer in the heat pipe allows the system to operate with a small elevation difference so that the entire system can be installed in the south wall.
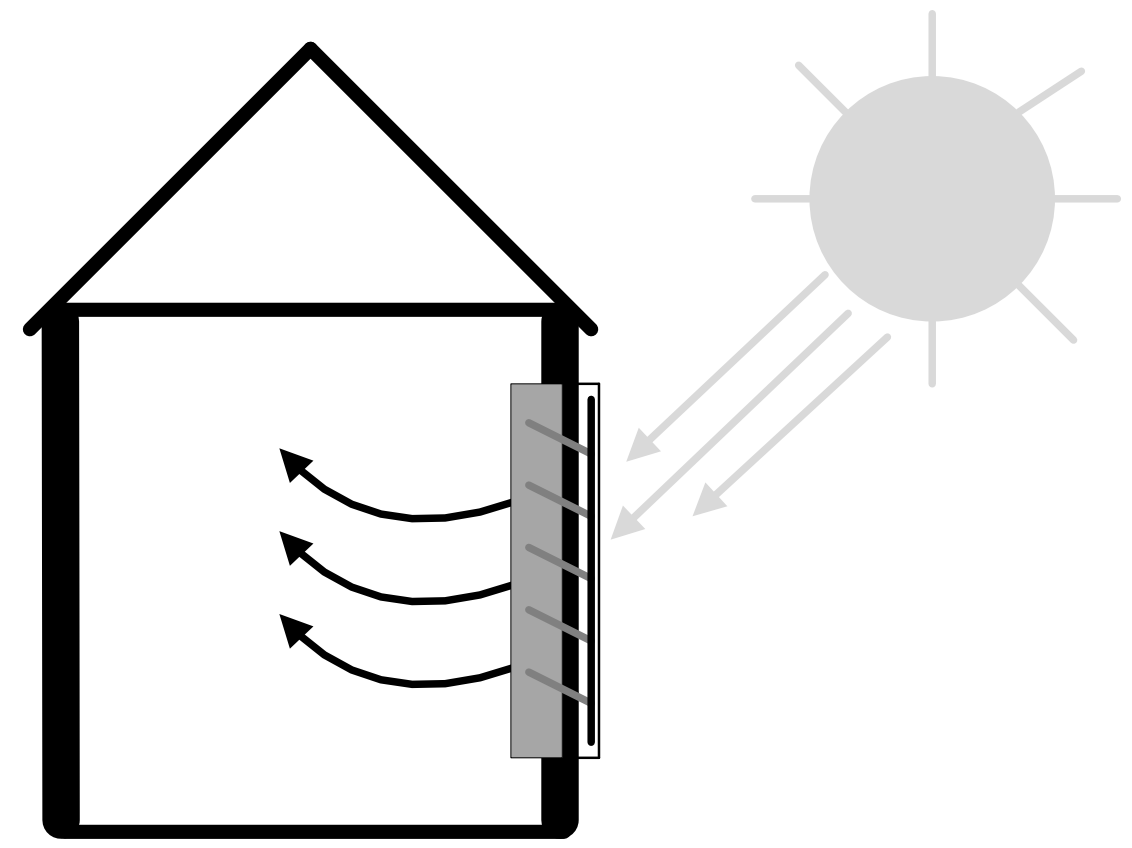

Figure 1. Schematic of full-scale heat pipe assisted solar wall prototype.

When the evaporator section is colder than the condenser section, the liquid heat transfer fluid remains in the evaporator and essentially no heat transfer takes place along the heat pipe. The result is low losses of heat flow away from the condenser. The large difference between forward and reverse heat transfer has caused heat pipes to be labeled as thermal diodes. 
Additionally, because of the effectiveness of boiling and condensing heat transfer, the heat pipe operates with small temperature gradients throughout. The result is extraordinary thermal conductance properties, with values 700 times greater than conduction in copper being reported [Dunn, 1994].

A full-scale heat pipe system that could be retrofitted onto existing walls was designed and tested by Susheela and Sharp [2001], with system efficiencies ranging from 60-80\% during sunny days. A bench-scale experimental model was tested by Albanese, et al. [2012], primarily based on design improvements recommended by Susheela and Sharp. A low-iron glass cover, a high-performance selective absorber surface, and a refrigerant fill level of $120 \%$ of the evaporator volume resulted in the highest average system thermal efficiency of $85 \%$.

Robinson, et al. [2013] continued the research of Albanese, et al. by testing a full-scale experimental prototype of similar design. The unit consisted of five individual heating units, each containing an absorber plate, heat pipe and storage tank (Fig. 1). The absorber material was aluminum coated with a black chrome selective surface, the heat pipes were 1 inch nominal diameter copper tubes, and each storage tank contained approximately 17 gallons of water. A maximum daily peak thermal efficiency of $83.7 \%$ and average daily peak thermal efficiency of $63.4 \%$ were measured. On cold, sunny days, the thermal storage was heated to temperatures well above the threshold for providing significant energy to the room. It was observed that useful gains typically commenced two to three hours after sunrise. The longest consecutive period of significant daytime cloud coverage was four days, yet heat delivery to the room from storage remained positive, and was never less than 40 Watts. For sunny days following any period of cloudy days, thermal storage temperatures were quickly restored to levels observed prior to the onset of the low-insolation period. Undesirable characteristics of the testing site included surface 
azimuth $10^{\circ}$ east of south, an existing overhang and side protrusion shading the absorbers at times during the testing period, and no independent control of room temperature (an auxiliary heater provided additional internal gains to the room).

Based on these results, computer simulations were used to model significant modifications to the Robinson, et al. [2013] prototype, and an improved full-scale prototype was designed and constructed. In addition, a passive solar test facility, designed to provide better testing conditions, was constructed on the campus of the University of Louisville. The facility consisted of two $3.66 \mathrm{~m}$ by $3.66 \mathrm{~m}$ (12' by 12') rooms, with the previous full-scale model [Robinson, et al. 2013] and the new design installed in each room, respectively. This paper will compare the performance of the two systems tested under identical conditions during January and February of 2013.

\section{METHODS}

\subsection{Computer Modeling}

A thermal network approach was used, similar to Albanese et al. [2012], who adapted the methods of Susheela and Sharp [2001] and Corliss [1979]. The thermal network for the new model of the heat pipe system is shown in Figure 2. 


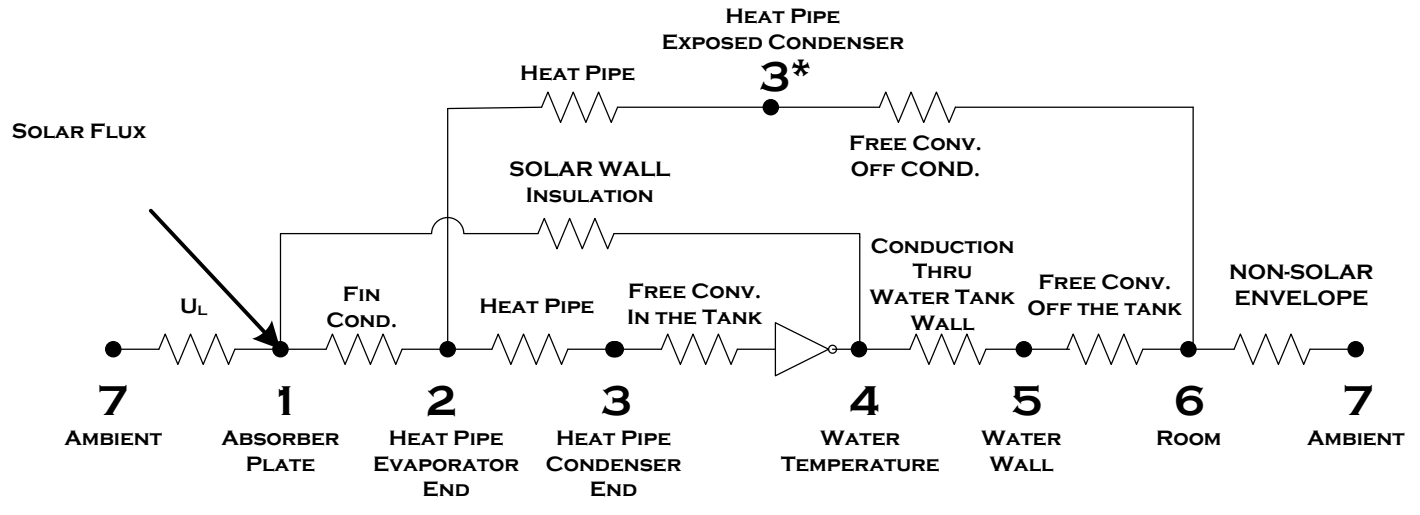

Figure 2. Thermal network for the heat pipe assisted solar wall with one or more condensers exposed directly to room air.

Using a central difference discretization scheme for conservation of energy among nodes, all nodal temperatures were simultaneously solved as a function of time from a set of initialized temperatures, using Typical Meteorological Year weather data (TMY3). For heat transfer coefficients dependent on nodal temperatures, iterations were used accordingly. Room nodal temperature was restricted, to simulate auxiliary heating and venting, within a defined room comfort range of 18.33 to $23.9^{\circ} \mathrm{C}\left(65\right.$ to $\left.75^{\circ} \mathrm{F}\right)$.

The potential to provide increased heat to the room during early-morning hours was investigated by modifying the heat pipe system so that one or more condensers were exposed directly to room air. This change provided a quicker transient response at the onset of insolation, for early energy transfer from the absorbers directly to the room when outdoor temperature is typically low and thermal mass has been depleted. To simulate the free condenser, a conductance was added between the condenser end of the heat pipe and the room (Figure 2). The conductance between the condenser and the water, the mass of the water and the conductances through the tank wall and to the room were all decreased to represent the fewer number of tanks. 
The heat transfer from the exposed condenser to room air was represented by a free convection Nusselt number for a heated tube [Incropera \& Dewitt, 2011]

$$
N u_{D}=\left[0.60+\frac{0.387 R a_{D}^{1 / 6}}{\left(1+(0.559 / \mathrm{Pr})^{9 / 16}\right)^{8 / 27}}\right]^{2}
$$

where $\operatorname{Pr}$ is the Prandtl number, and the Rayleigh number is [Incropera \& Dewitt, 2011]

$$
R a_{D}=\frac{g \beta\left(T_{3}-T_{6}\right) D^{3}}{v \alpha}
$$

where $g$ is the acceleration due to gravity, $\beta$ is the volumetric coefficient of thermal expansion for the room air (taken as the inverse of the film temperature between the condenser and room), $D$ is the outside diameter of the condenser, $v$ is the kinematic viscosity, $\alpha$ is the thermal diffusivity, and $T_{3}$ and $T_{6}$ are the temperatures of the condenser and room, respectively (Fig. 2). The normalized heat transfer coefficient, $k_{3 * 6}$, between the exposed condenser and room air was

$$
k_{3 * 6}=N_{\exp }\left(\frac{N u_{D} k_{r}}{D}\right) \frac{A_{c o n d}}{A_{c}}
$$

where $N_{\text {exp }}$ is the number of condensers exposed directly to room air, $k_{r}$ the thermal conductivity of the room air, $A_{\text {cond }}$ is the condenser area, and $A_{c}$ is the collector area. Thermal conductance values for the network shown in Figure 2 are provided in Table 1. All conductance values are normalized by the collector area.

Table 1. Description of thermal conductance values used for heat pipe wall thermal network models.

\begin{tabular}{|c|c|}
\hline $\begin{array}{c}\text { Conductance Value } \\
\left(\mathbf{W} / \mathbf{m}^{2} \mathbf{K}\right)\end{array}$ & Description \\
\hline$k_{71}$ & Overall collector loss coefficient \\
\hline$k_{12}$ & Absorber fin conduction to the working fluid \\
\hline$k_{23}$ and $k_{23 *}$ & $\begin{array}{c}\text { Fluid heat transfer from evaporator to condenser, thermal } \\
\text { conduction through heat pipe wall \& insulated wall - when } \\
T_{1}>T_{4} \text { for condenser in storage and } T_{1}>T_{6} \text { for condenser in room }\end{array}$ \\
\hline
\end{tabular}


Key parameters used for the simulations were a load to collector ratio (LCR) of 10 $\mathrm{W} / \mathrm{m}^{2} \mathrm{~K}$ and a defined room comfort temperature range of $18.33^{\circ} \mathrm{C}$ to $23.9^{\circ} \mathrm{C}\left(65^{\circ} \mathrm{F}\right.$ to $\left.75^{\circ} \mathrm{F}\right)$. All additional baseline parameters and calculated thermal network heat transfer coefficients were identical to Albanese, et al. [2012].

Annual heating load per unit collector area, $q_{a, h l}$, was

$$
q_{a, h l}=\sum_{\text {year }} k_{67}\left(T_{b}-T_{7}\right)^{+} \Delta t
$$

when the ambient temperature $\left(T_{7}\right)$ was below the commonly used base temperature $\left(T_{b}\right)$ of $18.33^{\circ} \mathrm{C}\left(65^{\circ} \mathrm{F}\right)$, and was zero otherwise, where $\Delta t$ is the time interval. Annual auxiliary heating load per unit collector area, $q_{a, a u x}$, was

$$
q_{a, \text { aux }}=\sum_{\text {year }}\left[k_{67}\left(T_{6}-T_{7}\right)-k_{56}\left(T_{5}-T_{6}\right)^{+}-k_{3^{*} 6}\left(T_{3^{*}}-T_{6}\right)^{+}\right] \Delta t
$$

when ambient temperature was less than room temperature $\left(T_{7}<T_{6}\right)$, and room temperature dropped to the lower comfort limit $\left(T_{6}=18.33^{\circ} \mathrm{C}\right)$. The asterisk superscript for $T_{3}$ in the third term within the summation brackets denotes the temperature of condenser(s) directly exposed to room air. The second and third term within the summation brackets represent the contribution from the heat pipe system to serving the heating load, and the difference between these terms and 
the first term (which is different from the heating load in that room temperature $T_{6}$ may exceed $T_{b}$ ) represents the auxiliary requirement. The calculated auxiliary heat was added during each time step to maintain the room at the lower comfort limit. System solar fraction, $S F$, represents the percentage of the annual heating load that is served by the heat pipe system

$$
S F=1-\frac{q_{a, a u x}}{q_{a, h l}}
$$

\subsection{Experiments}

\subsubsection{Passive Solar Test Facility (PSTF)}

The $3.66 \mathrm{~m}$ by $7.32 \mathrm{~m}$ (12' by 24') facility is divided into two identical $3.66 \mathrm{~m}$ by $3.66 \mathrm{~m}$ (12' by $12^{\prime}$ ) rooms to allow two systems to be compared side-by-side under the same weather conditions. Structural insulated panels (SIPs) were used for the building envelope, $0.30 \mathrm{~m}$ (12”) thick panels with an R-value of $7.93 \mathrm{~m}^{2} * \mathrm{~K} / \mathrm{W}\left(45 \mathrm{ft}^{2} \mathrm{~F} * \mathrm{hr} / \mathrm{Btu}\right)$ for the floor and walls, and 0.41 $\mathrm{m}(16 ")$ for the roof with an insulating value of $11.10 \mathrm{~m}^{2} * \mathrm{~K} / \mathrm{W}(\mathrm{R}-63)$. A $0.30 \mathrm{~m}$ thick panel separates the two rooms. To reduce infiltration, all joints between panels were caulked on both the interior and the exterior. Rough openings in the south wall were provided to accommodate passive solar systems. The overhang above the south openings is short to eliminate shading during the heating season. An image of the south wall of the building with the previous prototype in the west room and the new prototype in the east room is shown in Figure 3. 


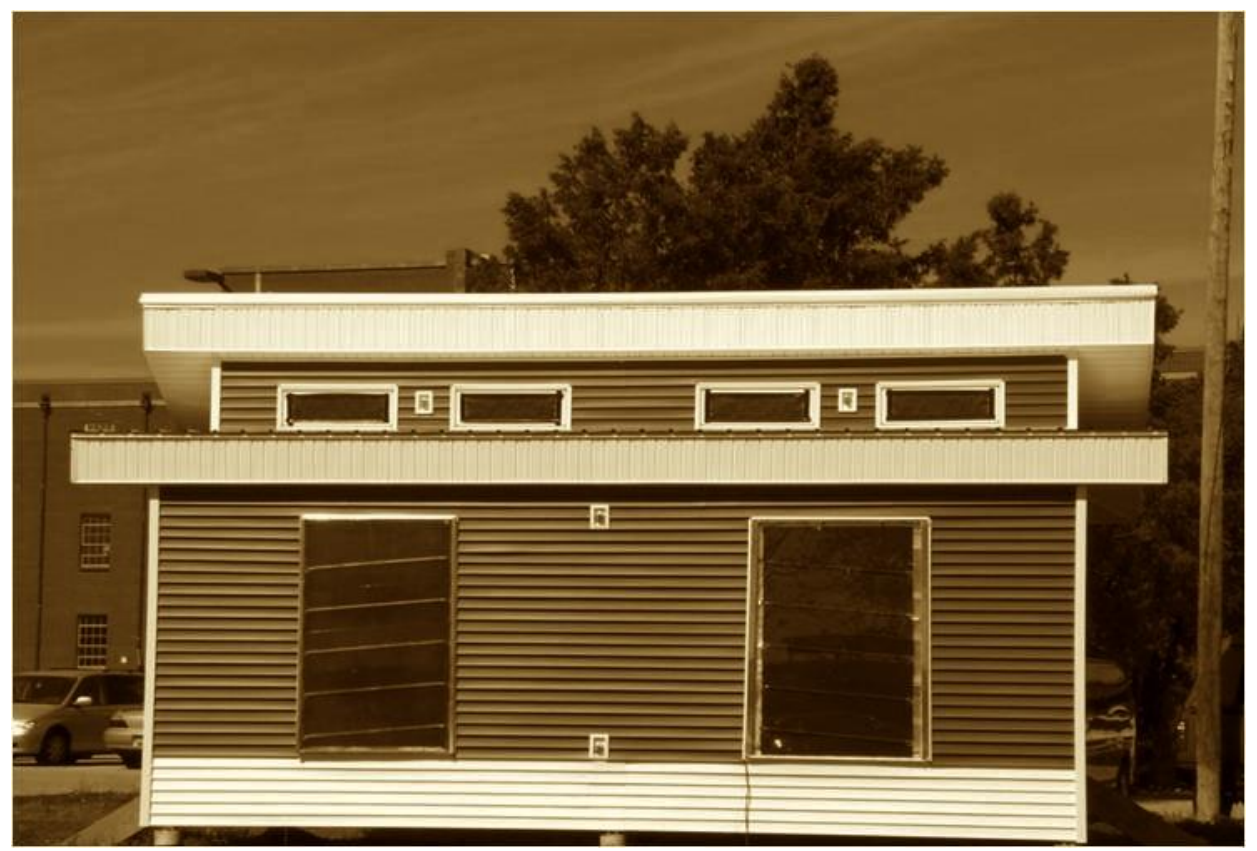

Figure 3. South view of the passive solar test facility. The collector for the previous prototype can be seen on the west (left) side of the wall, and the collector for the new prototype is on the east (right) side.

Doors were installed on the east and west for access to the rooms. A $0.99 \mathrm{~m}$ by $0.69 \mathrm{~m}$ (39" by 27") four-pane window of $1.7 \mathrm{~m}^{2} * \mathrm{~K} / \mathrm{W}$ (R-9) was installed on the north side of each room for ventilation and emergency egress. Two $0.38 \mathrm{~m}$ by $0.99 \mathrm{~m}$ (15" by 39 ") four-pane windows were installed in the clerestory section of each room for ventilation and daylighting. The overhang of the roof above the clerestory windows allows beam insolation to enter the windows during the winter months (October through April) and shades them during the summer. These windows were covered with an opaque material to eliminate additional solar gains during tests of the heat pipe systems. Electricity was supplied to the building for powering data acquisition hardware only. No auxiliary heating was supplied to the rooms.

The overall building heat loss coefficient (UA) was calculated from the rated loss coefficients for the components of the envelope and from measured infiltration using a blower door test apparatus. The number of Air Changes per Hour (ACH) was found in accordance with 
ASTM International Standard E-779 [2010]. Half the overall UA was assigned to each system. Heat exchange between the two rooms through the interior wall was neglected (supporting information is in Section 3.2.).

\subsubsection{Heat Pipe System Modifications}

Compared to the previous prototype (Figure 1) [Robinson et al. 2013], the new design (Figure 4) included copper absorbers soldered to the evaporator sections, instead of aluminum absorbers bonded with epoxy, reducing thermal resistance between the absorbers and evaporators. A new glass cover was used with improved solar transmittance at normal incidence of $93 \%$, versus $89 \%$ for the previous system. While the thermal diode effect prevents heat transfer by convection within the heat pipes when the condenser is warmer than the evaporator, conduction along the copper adiabatic section accounted for 39\% of thermal losses between the absorber and storage for the previous design [Robinson et al. 2013]. Replacing the copper (thermal conductance of $401 \mathrm{~W} / \mathrm{m} * \mathrm{~K})$ adiabatic sections with DPM rubber $(0.06 \mathrm{~W} / \mathrm{m} * \mathrm{~K})$ decreased this source of thermal bridging by $99.98 \%$. The adiabatic sections were also extended to allow $0.30 \mathrm{~m}(12$ ") of insulation (the same as the SIPS panels) between the absorber and storage. The previous unit had $0.09 \mathrm{~m}$ (3.5") of insulation. 


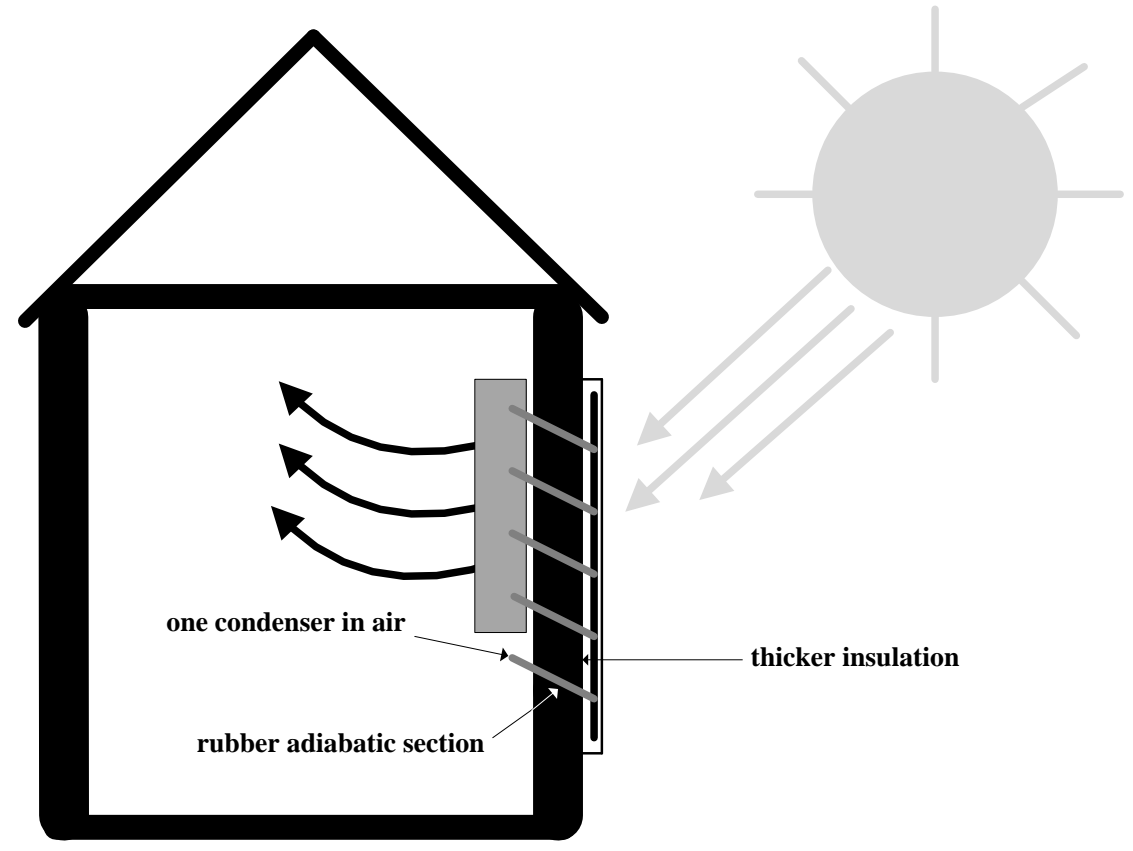

Figure 4. Schematic of a new model of the heat pipe wall prototype highlighting significant design modifications of the previous model.

In the new prototype, one of the five condenser sections was exposed directly to room air to increase heating of the room during early-morning hours. All other design parameters, including heat pipe, working fluid, and storage tank dimensions and materials were identical to the previous model [Robinson et al. 2013].

\subsubsection{Instrumentation}

A data acquisition system was placed in each room of the solar test facility. A National Instruments chassis was used in conjunction with an SCXI 160016 bit digitizer and an SCXI 1102B isolation amplifier with an SCXI 1303 thermocouple module. LabVIEW software was used to log the data at a sampling rate of $0.01667 \mathrm{~Hz}$. Two pyranometers were mounted between the south wall openings, one aligned with the top and the other with the bottom of the openings.

For each prototype, four T-type thermocouples were placed on the central absorber, three on each central evaporator, and two inside each individual storage tank. Additional placement of 
thermocouples included one attached to each tank wall to measure tank surface temperature, two placed in each room to measure room temperature, and two placed outside to measure ambient air temperature. The new prototype contained an additional two thermocouples placed on the exposed condenser.

\subsubsection{Data Analysis}

Data was collected and analyzed for the new prototype from January through February of 2013. All measured temperatures were averaged over hourly intervals. Thermal efficiency of the system, $\eta$, was calculated using

$$
\eta=\frac{\dot{Q}_{u}}{S A_{c}}
$$

where $S$ is the solar power received by the collector per unit area and $\dot{Q}_{u}$ is the useful power delivered by the heat pipes to storage and to the room. For each prototype, power was calculated for each heating unit, whether to a storage tank or the single condenser directly exposed to air. Thus, the total useful power for each system is

$$
\dot{Q}_{u}=\frac{M c_{p} \Delta T_{s}}{\Delta t}+\frac{T_{s}-T_{r}}{R_{s r}}
$$

where $M$ is the mass of the water in the storage tank, $c_{p}$ is the specific heat of the water, $\Delta T_{s}$ is the water temperature change during the one hour time interval $\Delta t, T_{s}$ and $T_{r}$ are the temperatures for the water and room, respectively, and $R_{s r}$ is the total thermal resistance from the thermal mass to the room air. The first term on the right-hand side of equation 8 represents the net power to the storage tank $\left(\dot{Q}_{S}\right)$, and the second term represents the power transfer from the storage tanks to the room $\left(\dot{Q}_{\text {out }}\right)$. Days for which $\dot{Q}_{u}$ was negative between 9am and 5pm signified cloudy 
conditions, and were discarded from the analysis. A thermal resistance network for $R_{s}$ is shown in Figure 5.

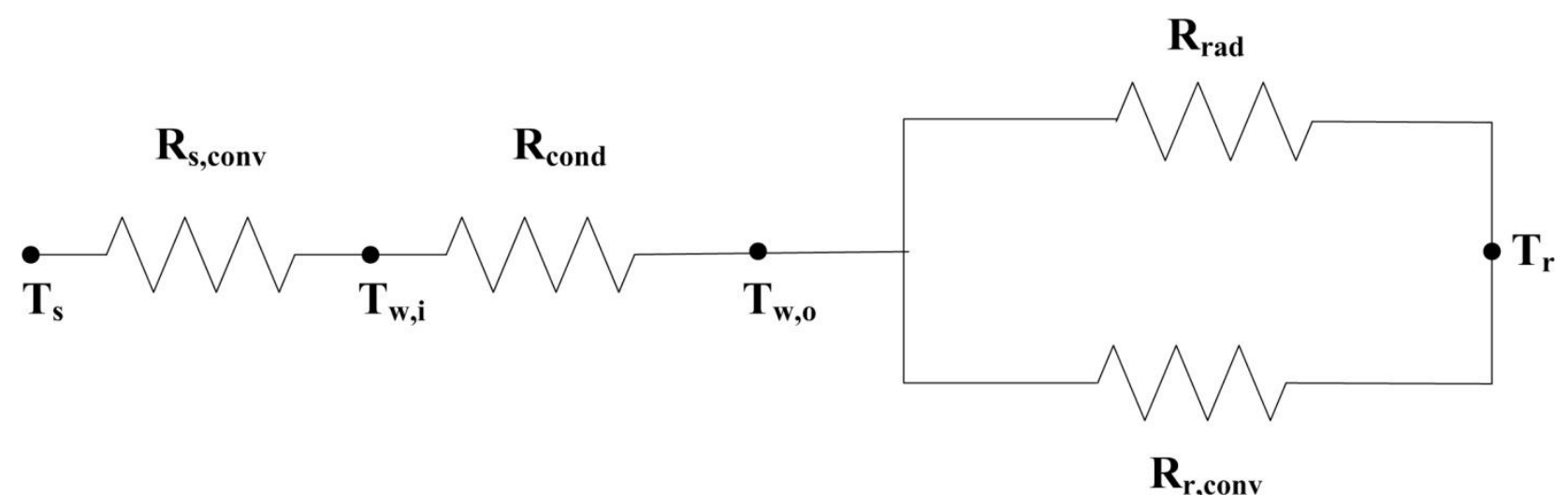

Figure 5. Thermal resistance network used to calculate $q_{\text {out }}$ for heating units with a thermal storage tank.

Applying the resistance network shown in Figure 5, $R_{s r}$ is

$$
R_{s r}=\frac{1}{h_{s, c o n v} A_{s}}+\frac{t_{w}}{k_{w} A_{s}}+\left(\frac{1}{h_{r a d} A_{s}}+\frac{1}{h_{r, c o n v} A_{s}}\right)^{-1}
$$

where $A_{s}$ is the total heat transfer surface area of each tank exposed to room air, $t_{w}$ is the tank wall thickness, and $k_{w}$ is the thermal conductivity of the tank wall. On the right-hand side of Equation 9, the first term represents convective heat transfer to the inside surface of the tank wall, the second term is conduction through the tank wall, and the third and fourth terms constitute parallel radiation and convection, respectively, from the wall of the tank to the room. The convection coefficient for water or air is

$$
h_{s / r, c o n v}=\frac{k_{s / r} N u_{s / r, c o n v}}{L}
$$

where $k_{s / r}$ is the thermal conductivity with the subscript $s / r$ denoting the value for water or air, $L$ is the tank wall height, and the Nusselt number, $N u_{s / r}$ (developed for free convection from a vertical plate [Incropera \& DeWitt, 2011]), for water or air is dependent on whether convection conditions are laminar or turbulent. For laminar flow, the Nusselt number is 


$$
N u_{s, r}=0.68+\frac{0.67 R a_{s, r}^{1 / 4}}{\left(1+\left(0.492 / \operatorname{Pr}_{s, r}\right)^{9 / 16}\right)^{4 / 9}}
$$

For turbulent conditions, the Nusselt number is

$$
N u_{s, r}=0.825+\frac{0.387 R a_{s, r}^{1 / 6}}{\left(1+\left(0.492 / \operatorname{Pr}_{s, r}\right)^{9 / 16}\right)^{8 / 27}}
$$

Laminar to turbulent transition depended on the Rayleigh number

$$
R a_{s / r}=\frac{g \beta_{s / r} \Delta T_{s w / w r} L^{3}}{v_{s / r} \alpha_{s / r}}
$$

where $\Delta T_{s w}$ is the temperature difference between storage and the tank wall and $\Delta T_{w r}$ is the temperature difference between the tank wall and room. For $R a_{s t / r}<10^{9}$, free stream conditions are laminar, and when $R a_{s t / r}>10^{9}$, they are turbulent. The radiative heat transfer coefficient was found using

$$
h_{\text {rad }}=\varepsilon \sigma\left(T_{w}+T_{r}\right)\left(T_{w}^{2}+T_{r}^{2}\right)
$$

where $\varepsilon$ is the radiative emissivity of the water tank wall and $\sigma$ is the Stefan-Boltzmann constant.

For a condenser exposed directly to room air, $\dot{Q}_{\text {out }}$ is

$$
\dot{Q}_{\text {out }}=\frac{T_{c n d s r}-T_{r}}{R_{c n d s r}}
$$

where $T_{c n d s r}$ is the temperature of the exposed condenser and the thermal resistance network for $R_{\text {cndsr }}$ is shown in Figure 6. 


\section{Figure 6. Thermal resistance network used to calculate $q_{\text {out }}$ for a heating unit with the condenser exposed directly to room air.}

Applying the resistance network shown in Figure $6, R_{c n d s r}$ is

$$
R_{c n d s r}=\left(\frac{1}{h_{c n d s r} A_{c n d s r}}+\frac{1}{h_{r a d, c n d s r} A_{c n d s r}}\right)^{-1}
$$

where $A_{c n d s r}$ is the surface area of the condenser, and $h_{c n d s r}$ is

$$
h_{c n d s r}=\frac{k_{r} N u_{D}}{D}
$$

and

$$
h_{r a d, c n d s r}=\varepsilon_{c n d s r} \sigma\left(T_{c n d s r}+T_{r}\right)\left(T_{c n d s r}^{2}+T_{r}^{2}\right)
$$

where $\varepsilon_{c n d s e r}$ is the radiative emissivity of the copper condenser. The properties of the water in the tank and the air in the room were determined by interpolation from thermophysical property tables [Incropera \& DeWitt, 2011] at the average tank and room temperature(s) over the course of that hour.

Efficiency versus loss potential to insolation ratio, $\left(T_{s}-T_{a}\right) / S$, for the new system was also calculated, where $T_{a}$ is the ambient temperature. Conditions were determined in the same manner as Robinson et al. [2013] and were selected to conform as closely as possible to 
ASHRAE standard 93 [2010]. Because of the additional enthalpy associated with latent heat of the phase change fluid and a higher specific heat for the fluid (versus typically used water or antifreeze solutions), plus the additional thermal capacity of the collectors, the time constant for these passive systems is much larger than those for active systems. Thus ASHRAE 93 criterion that requires that insolation varies no more than $\pm 32 \mathrm{~W} / \mathrm{m}^{2}$ over intervals of 10 minutes or two collector time constants - whichever is greater - could not be met. However, by using two-hour intervals centered around solar noon, variation in insolation was limited to no more than 32 $\mathrm{W} / \mathrm{m}^{2}$ per 10 minutes, and incidence angles were also lowest.

\subsubsection{Error Propagation}

System efficiency (equation 7) depends on measurements of storage, room and condenser temperatures (Equations 8 and 15) and of insolation. In addition, each of these measurements is subject to digitization error by the data acquisition system. Therefore, the uncertainty in calculated system efficiency, $\mu_{\eta}$, was found using

$$
\mu_{\eta}=\sqrt{\left(\frac{\partial \eta}{\partial \Delta T_{A}} \mu_{\Delta T_{s}}\right)^{2}+\left(\frac{\partial \eta}{\partial \Delta T_{B}} \mu_{\Delta T_{s r}}\right)^{2}+\left(\frac{\partial \eta}{\partial \Delta T_{C}} \mu_{\Delta T_{\text {rndsr }}}\right)^{2}+\left(\frac{\partial \eta}{\partial S} \mu_{S}\right)^{2}}
$$

where $\Delta T_{s}$ is the storage temperature difference from Equation $8, \Delta T_{s r}$ is the temperature difference between storage and room $\left(T_{s}-T_{r}\right)$ from Equation 8, $\Delta T_{c n d s r}$ is the temperature difference between the exposed condenser and room $\left(T_{c n d s r}-T_{r}\right)$ from Equation 15, and $\mu$ represents the uncertainty in temperature and insolation measurements, respectively.

For any arbitrary value of $\Delta T=T_{1}-T_{2}$

$$
\left(\frac{\partial \Delta T}{\partial T_{1}}\right)^{2}=\left(\frac{\partial \Delta T}{\partial T_{2}}\right)^{2}=1
$$

therefore the uncertainty for any $\Delta T$ is 
where $\mu_{\text {digit }}$ is the digitization error in each temperature measurement, which for the SCXI-1600 and SCXI-1102 modules was $\pm 0.027 \mathrm{~K} / \mathrm{level}$, and thermocouple uncertainty, $\mu_{t c}$, is roughly 0.1 $\mathrm{K}$ up to approximately $100^{\circ} \mathrm{C}$ [Ripple et al., 1994]. Thus

$$
\mu_{\Delta T_{s}}=\mu_{\Delta T_{s r}}=\mu_{\Delta T_{\text {ouds }}}=\sqrt{\mu_{\Delta T, t c}^{2}+\mu_{\Delta T, d i g i t}^{2}}
$$

resulting in an overall uncertainty in temperature measurement of $0.146 \mathrm{~K}$.

The pyranometers have an overall error of $\pm 3 \%$ of the measured value, as specified by the manufacturer Kipp and Zonen. Accordingly, the maximum $\mu_{\eta}$ occurred at the maximum value of insolation measured during the testing period $\left(934.5 \mathrm{~W} / \mathrm{m}^{2}\right)$ and resulted in a maximum $\mu_{S}$ of $28.04 \mathrm{~W} / \mathrm{m}^{2}$. Values for each derivative in Equation 19 are shown in Table 2. The derivative associated with $\dot{Q}_{s t}$ represented the greatest uncertainty and the derivative associated with pyranometer measurement (insolation) represented the least uncertainty. The estimated uncertainty in system efficiency from Equation 19 was $\pm 3.50 \%$.

Table 2. Value for each derivative associated with overall uncertainty in calculated system efficiency.

\begin{tabular}{|c|c|}
\hline Derivative & Value \\
\hline$\partial \eta / \partial \Delta T_{s}$ & 0.2190 \\
\hline$\partial \eta / \partial \Delta T_{s r}$ & 0.0012 \\
\hline$\partial \eta / \partial \Delta T_{c n d s r}$ & 0.0018 \\
\hline$\partial \eta / \partial \Delta S$ & 0.0005 \\
\hline
\end{tabular}




\subsection{Matching simulations to full-scale performance}

In order to provide partial confirmation of computer simulations and acquire a better understanding of the full-scale PSTF prototype performance, simulation variables were adjusted to match the temperature trends obtained by the prototype over a 72-hour period from January 5 - 7. This period consisted of two sunny days (January 5 and 7) with a cloudy day in between (January 6). Initial modifications to the baseline algorithms consisted of matching dimensional parameters to those of the prototype and PSTF, including absorber, evaporator, condenser, adiabatic and tank dimensions, solar wall insulation materials and thicknesses, and an LCR equivalent to its calculated value. Additionally, since baseline simulations only accounted for the capacitance (product of the material specific heat and mass) of the water storage (node 4 in Figure 2), the effects of capacitance for additional nodes were evaluated. Initial capacitance added for the thermal mass in the room (node 6) consisted of the room air and OSB sheathing for the walls, floor and roof. This capacitance was increased from this initial value to achieve matching.

The overall collector loss coefficient $\mathrm{k}_{71}$ (Fig. 2, Table 1) is sensitive to forced convection due to wind velocity. Since wind speed was not measured during experimentation, $k_{71}$ could not be effectively calculated; thus measured temperatures - for each hour during the 72-hour period for the prototype absorber (node 1 in Figure 2) were imported into the matching simulations. Since certain nodal conductances in the thermal model were calculated based on wellestablished, empirically-validated correlations and formulas, these values were left unchanged, including absorber fin conduction $k_{12}$, condenser-to-water convection $k_{34}$, and water wall conduction $k_{45}$. The remaining parameters had lower certainty in their values and were adjusted accordingly for matching. 
The parameters adjusted included the capacitance of the room and the conductances for: working fluid heat transfer from the evaporator to condenser $k_{23}$, conduction through the solar wall $k_{41}$, heat transfer from the tank wall to the room $k_{56}$, and the LCR $\left(k_{67}\right)$. These values were adjusted until the average difference in temperature, over the 72-hour period, between simulated and experimental values for the evaporators, tanks, and room were less than or equal to $0.5 \mathrm{~K}$.

\section{RESULTS \& DISCUSSION}

\subsection{Computer simulations}

The higher thermal conductivity in the absorber of copper over aluminum resulted in a slight increase in solar fraction by $0.50 \%$ (Figure 7). The thicker wall reduced thermal losses from both storage and room to the cold ambient air, increasing solar fraction by an additional 4.92\%. Reductions in thermal bridging created by the rubber adiabatic section resulted in the greatest increase in solar fraction by an additional 5.32\%. The total improvement for all three changes was $10.7 \%$ 


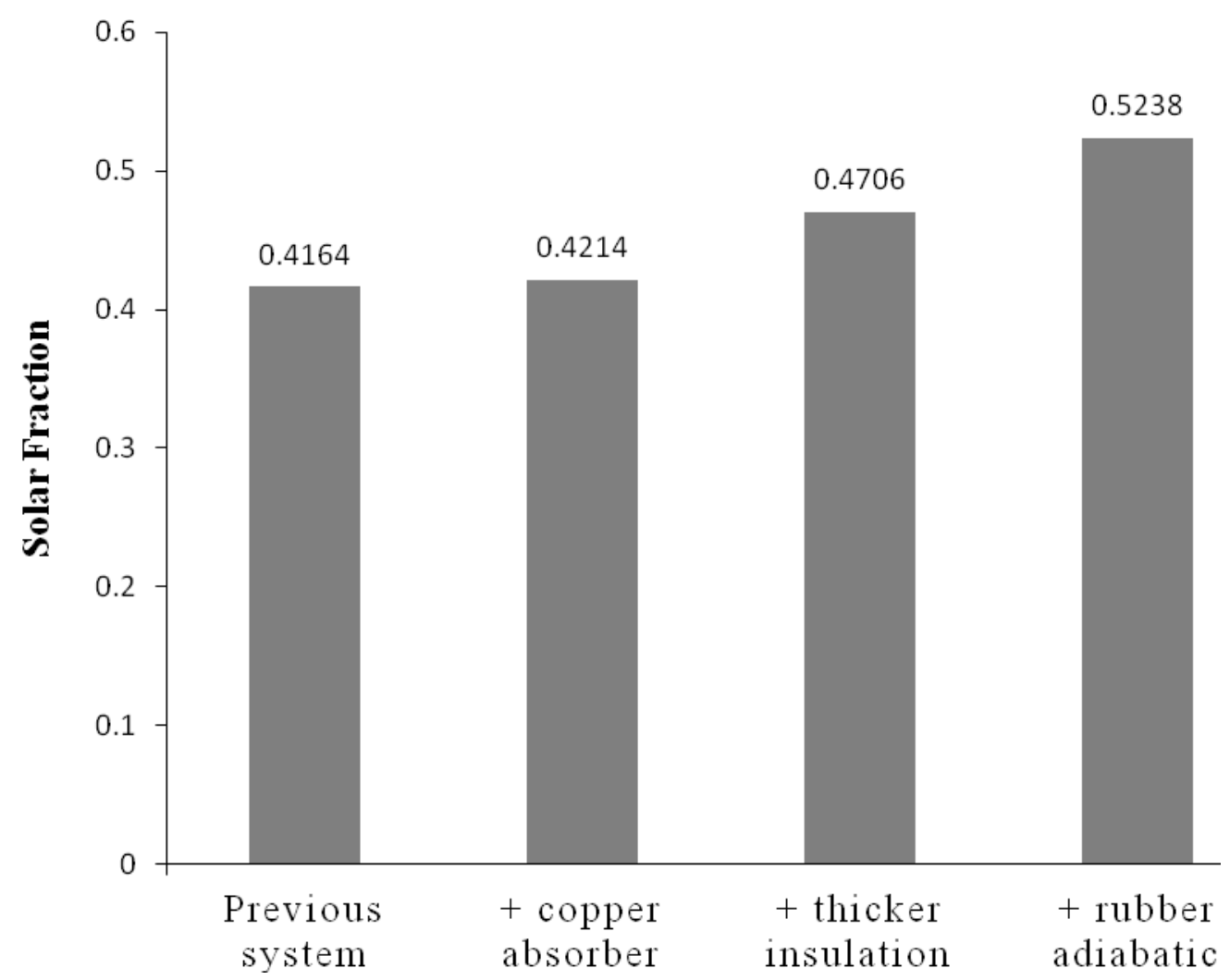

Figure 7. Solar fraction for the previous prototype and modifications implemented for the new prototype.

Exposing one or two condensers to room air increased the solar fraction in the morning more rapidly than the system with all condensers in tanks (Figure 8). However, the system with one condenser exposed to room air delivered more heat to the room in the early evening hours than either of the other two systems. Because of its smaller thermal capacity, the system with four tanks lost solar fraction during the night at a greater rate, and by morning, its contribution was approximately the same as the baseline system. Simulations also confirmed that exposing condenser sections to the room improved annual performance of the heat pipe system (Fig. 9). The condenser configuration with four in tanks and one exposed to room air achieved the best balance between early-morning heating and thermal storage for nighttime heating, and combined with the improvements shown in Fig 7, achieved an increase in solar fraction of $20.9 \%$. 


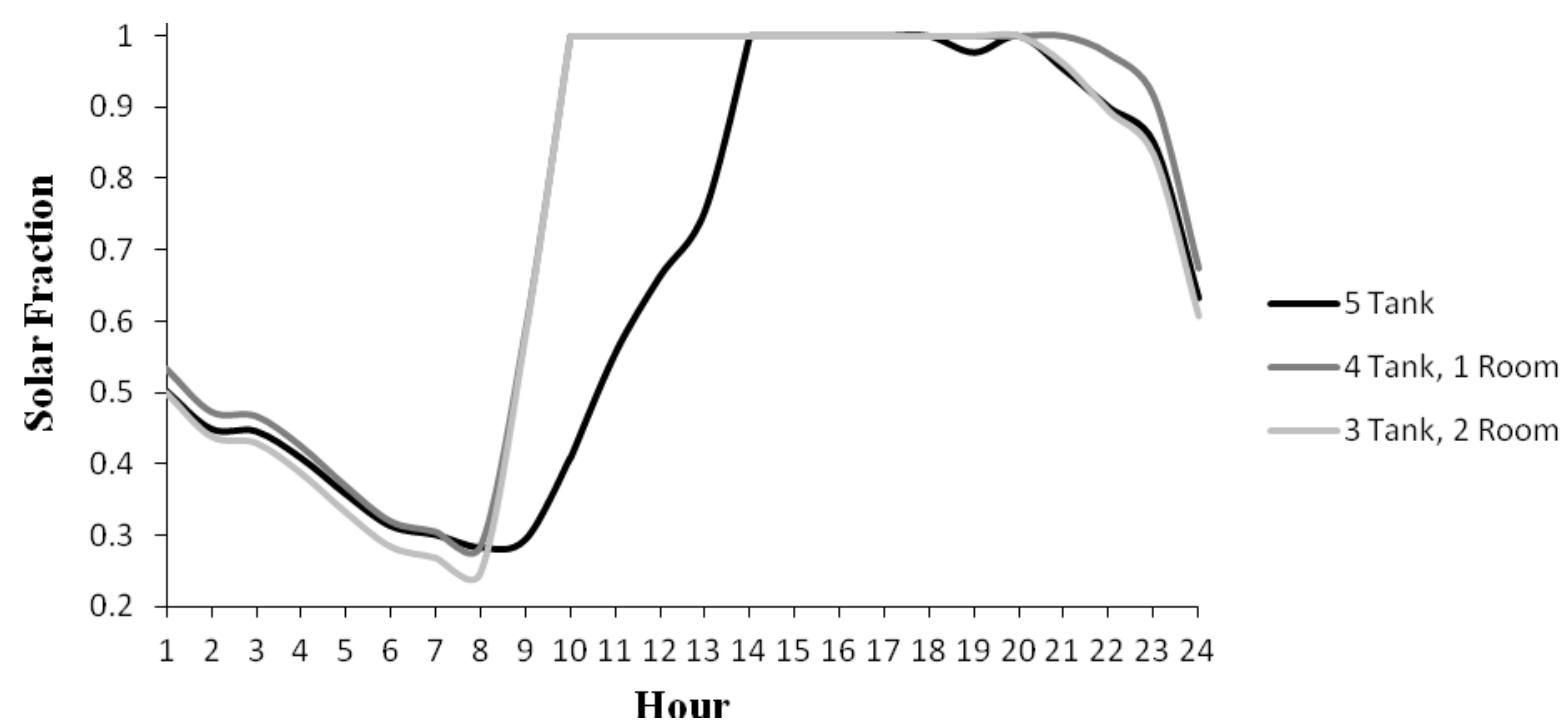

Figure 8. Simulated solar fractions on January 15 for three condenser unit configurations.

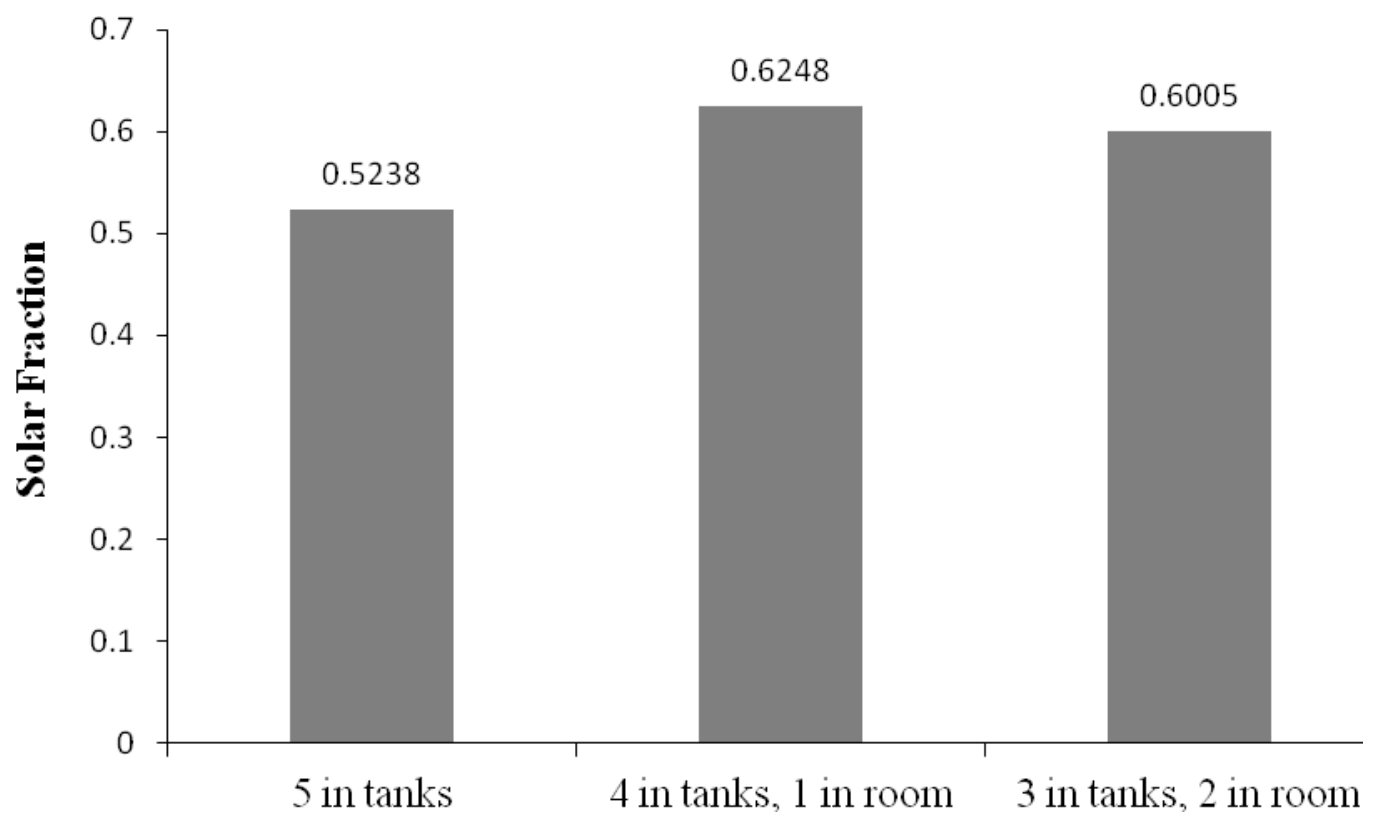

Figure 9. Annual solar fraction for each condenser configuration.

\subsection{Passive solar test facility loss coefficient}


The calculated loss coefficients (UA) for the major components of the envelope for the solar test facility (for each room) are shown in Table 3. Blower door testing found an ACH of 0.1 .

Table 3. Rated R-values and calculated UA values for key components of one room.

\begin{tabular}{|c|c|c|}
\hline Building Component & R-value $\left(\mathbf{m}^{\mathbf{2}} * \mathbf{K} / \mathbf{W}\right)$ & $\begin{array}{c}\text { UA value } \\
(\mathbf{W} / \mathbf{K})\end{array}$ \\
\hline Clerestory Windows & 1.59 & 0.48 \\
\hline North Window & 1.59 & 0.43 \\
\hline Door & 1.85 & 1.00 \\
\hline Floor & 7.93 & 1.23 \\
\hline Roof & 11.10 & 0.92 \\
\hline Walls & 7.93 & 3.06 \\
\hline Infiltration & - & 1.81 \\
\hline- & Room Nonsolar & $\mathbf{8 . 9 3}$ \\
\hline & UA: \\
\hline
\end{tabular}

The power transfer between rooms through the adjoining wall, estimated using the average difference in room temperatures over the testing period, was only $9.7 \mathrm{~W}$. This rate is less than $1 \%$ of the average solar gains from the heat pipe systems, thus these heat losses and gains between rooms were neglected.

With a collector area for the heat pipe system prototypes of approximately $2.41 \mathrm{~m}^{2}$, the LCR for the prototypes installed in the passive solar test facility is approximately $3.7 \mathrm{~W} / \mathrm{m}^{2} \mathrm{~K}$. This LCR is significantly lower than that used for previous simulations characterizing typical buildings $\left(\mathrm{LCR}=10 \mathrm{~W} / \mathrm{m}^{2} \mathrm{~K}\right)$. Decreasing $\mathrm{LCR}$ by decreasing the building UA alone (or alternatively, increasing the collector area for a fixed building UA) can greatly increase the solar fraction (Figure 10). 


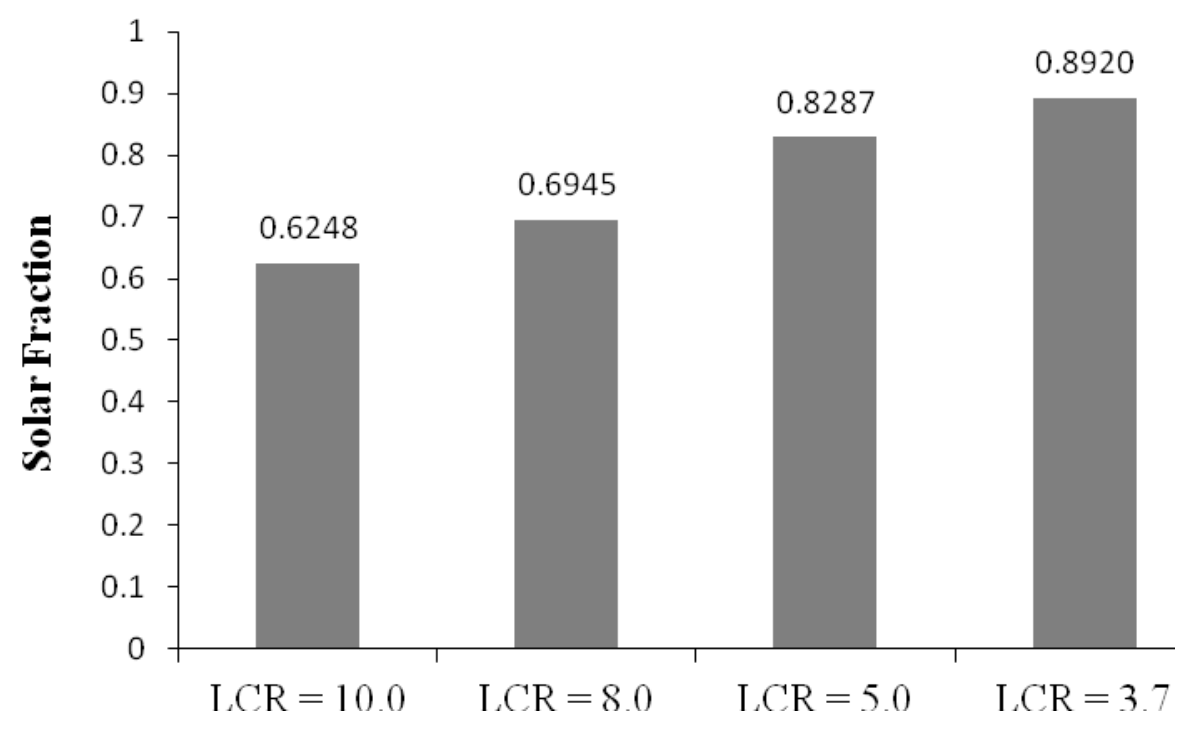

\section{Figure 10. Simulated annual solar fraction for the new system at four different Load-to- Collector ratios.}

\subsection{Heat pipe systems experiments}

Both absorbers exhibited similar rates of temperature increase during the onset of insolation, but the peak temperature and the difference between absorber and evaporator temperatures were both considerably smaller for the modified system during sunny days due to the higher conductivity of the copper absorber and the soldered joint between the absorber and the evaporator (Figure 11). Although higher absorber temperatures were obtained for the previous design, the new design achieved greater evaporator temperatures, indicating greater heat transfer to the working fluid in the heat pipe. The absorber for the modified system cooled to ambient temperature during the night, while the absorber for the previous system remained warm because of thermal bridging along its copper adiabatic section. 


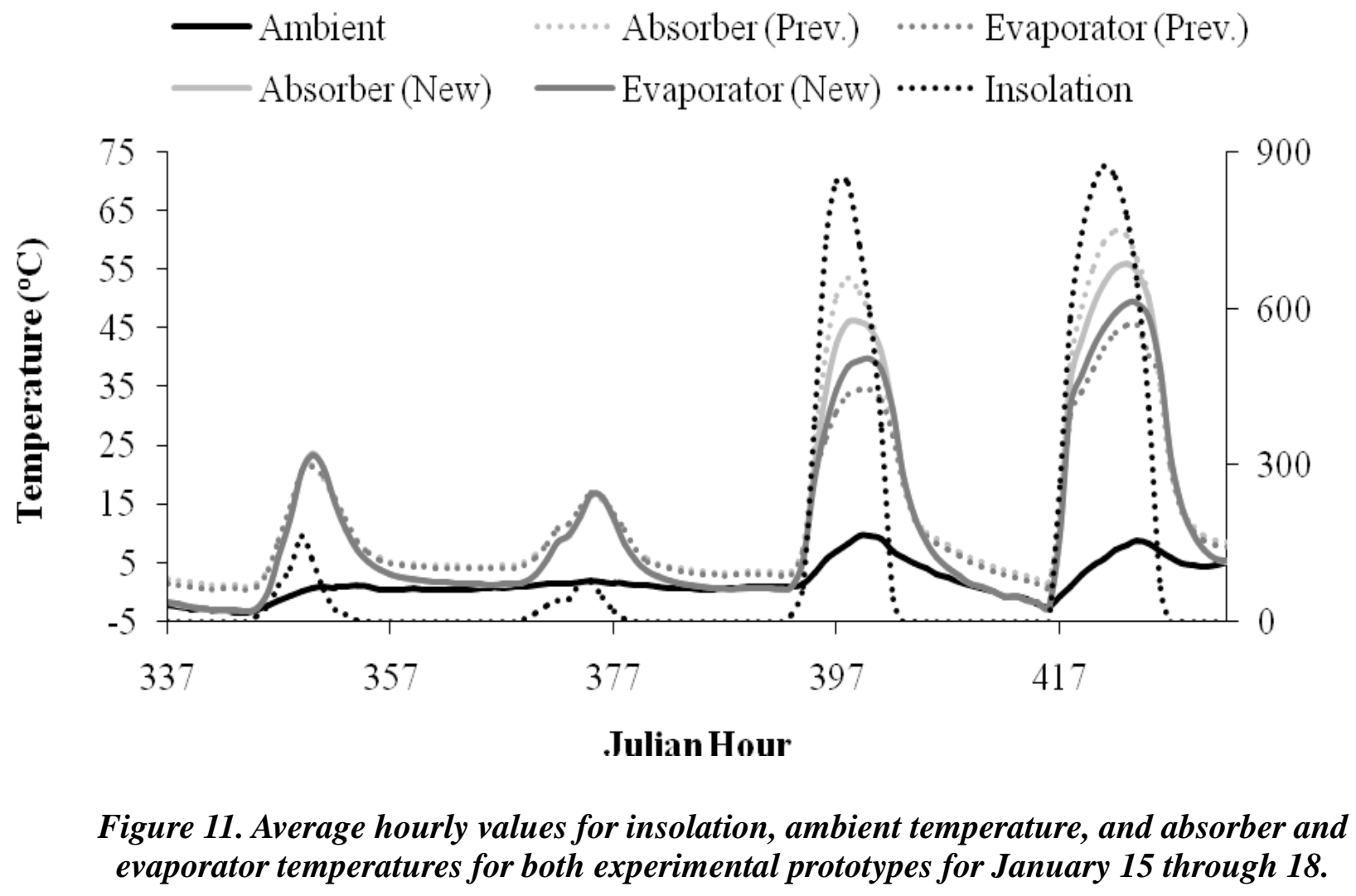

At the onset of daily insolation, the temperature in the tanks increased at a greater rate for the new design than that of the previous design due to greater conductance between absorber and evaporator (Figure 12). The directly exposed condenser, as well as more convective surface area between the storage tanks and the room, contributed to the higher rate of increase in room temperature for the new system. (With the thicker insulation of the new design, the thermal storage tanks extended entirely into the room, whereas the tanks of the previous model were recessed into the wall. The total convective surface area for the four tanks of the new system was $3.64 \mathrm{~m}^{2}$. The previous system contained an additional tank, yet had a total convective surface area of only $1.99 \mathrm{~m}^{2}$.) Even though it contained less thermal mass, a greater temperature difference between the tanks and ambient, and more convective surface area for heat transfer to the room, the rate of temperature decrease during nighttime for the new system was nearly 
equivalent to the previous model - primarily due to reduced nighttime losses from increased insulation and less thermal bridging. This trend of higher energy gains during sunny days and similar losses during cloudy days and nighttime compounded net gains over time. Room temperature was higher in the new system by $3.9^{\circ} \mathrm{C}$ at the beginning of February $14\left(22.7^{\circ} \mathrm{C}\right.$ for the previous vs. $26.6^{\circ} \mathrm{C}$ for the new), $5.1^{\circ} \mathrm{C}$ at the end of February $14\left(25.2^{\circ} \mathrm{C}\right.$ vs. $\left.30.3^{\circ} \mathrm{C}\right), 5.5^{\circ} \mathrm{C}$ at the end of February $15\left(21.8^{\circ} \mathrm{C}\right.$ vs. $\left.27.3^{\circ} \mathrm{C}\right)$, and $8.1^{\circ} \mathrm{F}\left(19.7^{\circ} \mathrm{C}\right.$ vs. $\left.27.8^{\circ} \mathrm{C}\right)$ by the end of February 16.

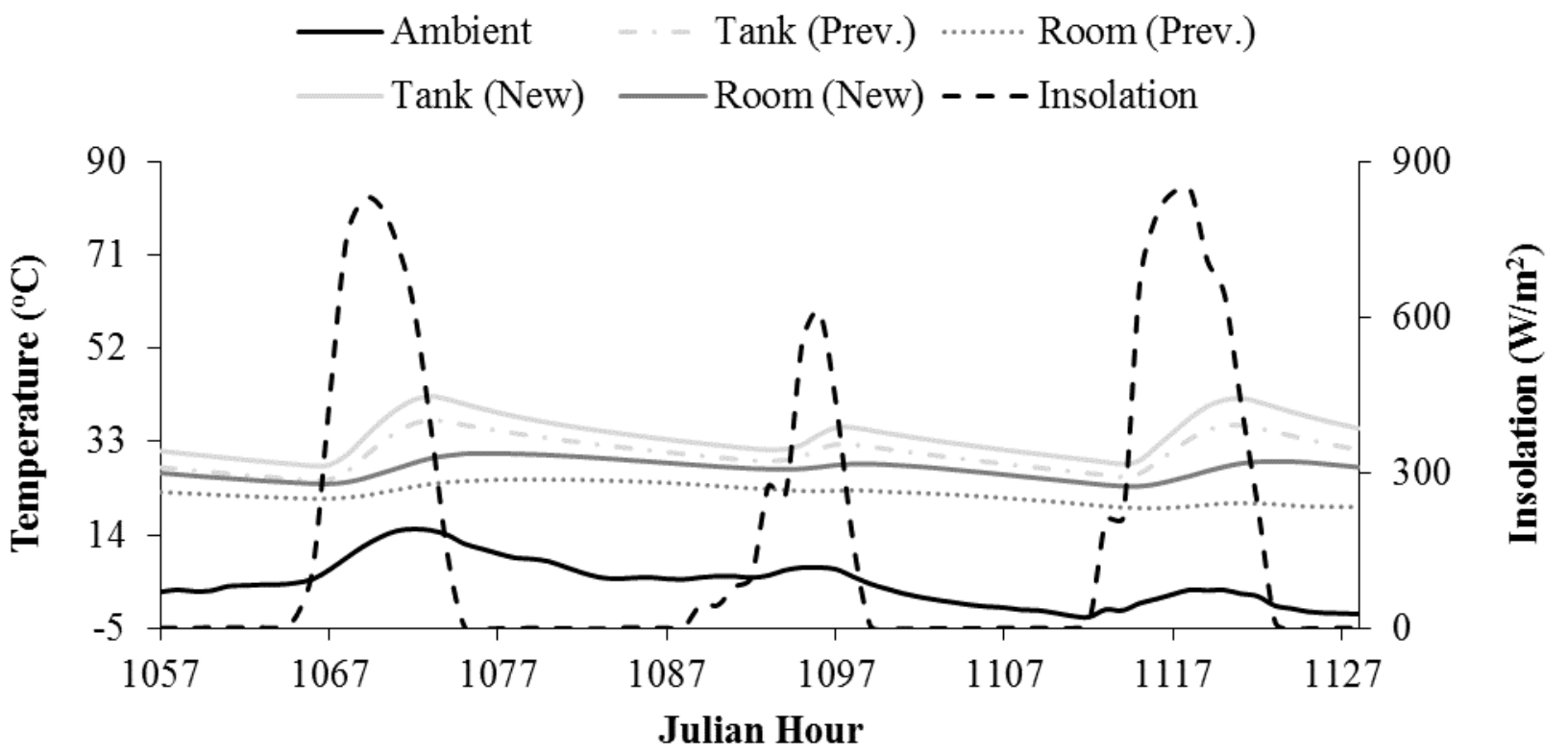

Figure 12. Average hourly values for insolation, ambient temperature, and tank and room temperatures for both experimental prototypes for February 14 through 16.

Over the entire testing period, average tank temperatures for the new system was $13.4 \%$ higher than the previous system, and average room temperature was $24.6 \%$ higher (Figure 13). The average ambient temperature during the entire testing period was $4.1^{\circ} \mathrm{C}\left(39.4^{\circ} \mathrm{F}\right)$. The longest period of cloudy days with insignificant insolation was five days (January $27-31$ ). During this period, the new system maintained hourly average tank and room temperatures of 22.6 and $21.0^{\circ} \mathrm{C}$, respectively, while the previous system had temperatures of 20.2 and $17.9^{\circ} \mathrm{C}$, 
respectively. The average daily peak thermal efficiency for the new and previous models were $85.0 \%$ and $80.7 \%$, respectively, with the new system attaining a maximum peak thermal efficiency of $92.74 \%$ compared to $90.6 \%$ for the previous.

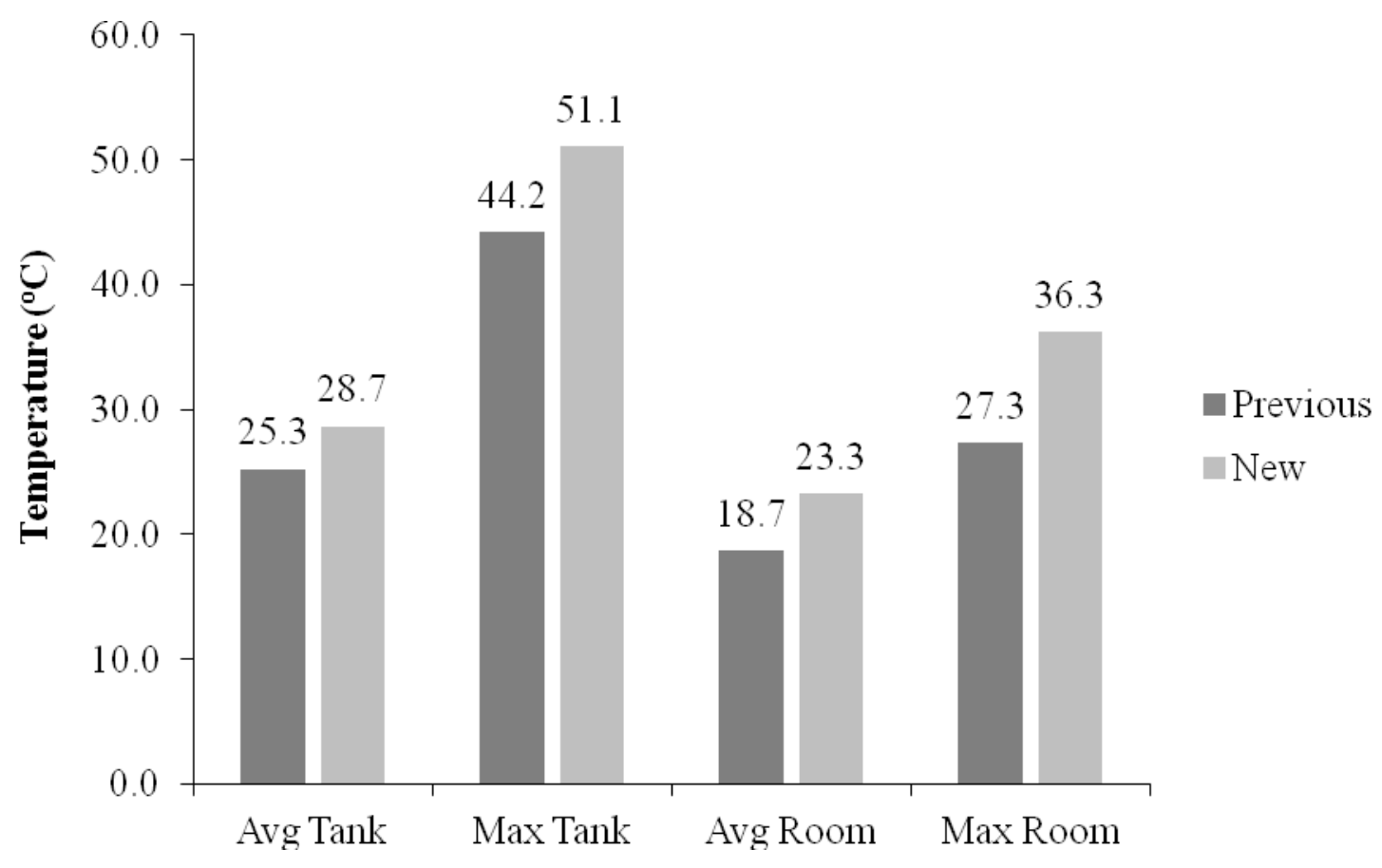

Figure 13. Average and maximum tank and room temperatures for both experimental prototypes over the entire testing period.

Efficiency data points using the criteria of section 2.2.4 were centered around solar noon, where beam radiation angle of incidence varied from $30.6^{\circ}$ (January 3) to $40.3^{\circ}$ (February 17) (Figure 14). Partial compliance with ASHRAE 93 was achieved by selecting data with insolation variation no greater than $\pm 32 \mathrm{~W} / \mathrm{m}^{2}$ per 10 minutes. The slope and intercept of the trendline are similar to the heat removal factor $*$ overall loss coefficient, $F_{R} U_{L}$, and heat removal factor $*$ transmittance absorptance product, $F_{R}(\tau \alpha)$, respectively, for active collectors. The intercept for the heat pipe system is on the high end, and the slope close to the average, of the range of $F_{R}(\tau \alpha)$ and $F_{R} U_{L}$ values, respectively, for glazed flat plate collectors [SRCC, 2014]. This high intercept (79.3\% for the new system versus $74.1 \%$ for the old system at its initial location (prior to 
installation in the PSTF)) is likely the result of the enhancement of heat transfer by the thick copper absorbers and boiling heat transfer in the evaporator.

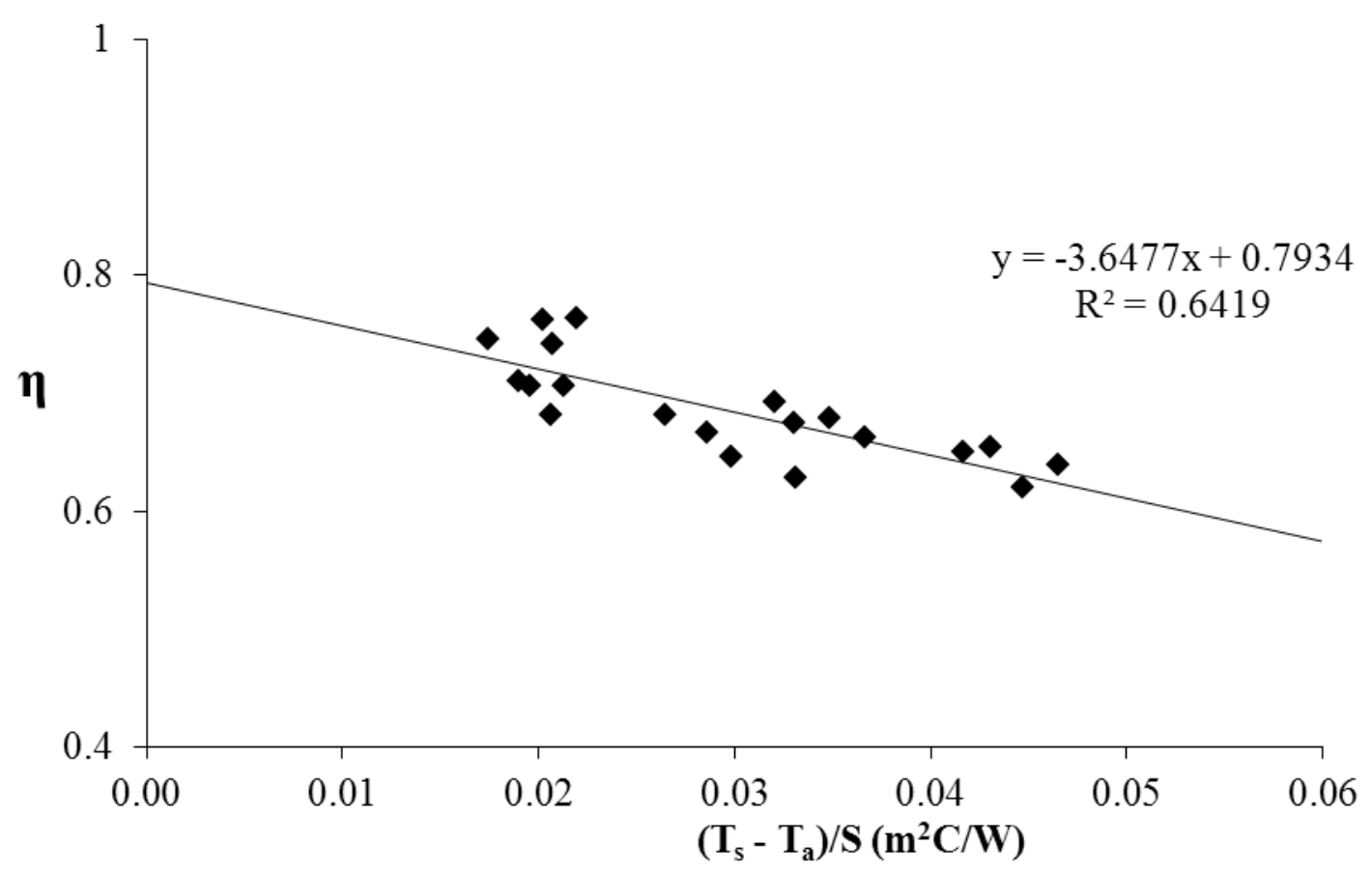

Figure 14. New system efficiency versus loss potential/insolation ratio.

\subsection{Matching simulations and experiments}

Conductances that were changed as a result of the matching process are shown in Table 4. Conductance $k_{56}$ was adjusted but is temperature-dependent, thus minimum and maximum values are listed. Simulated behavior was unaffected by adding capacitances for the evaporators, condensers, and tank wall (nodes 2, 3 and 5, respectively from Figure 2), thus these capacitances were removed to regain simplicity of the model.

Higher absorber fin conduction $k_{12}$ (Figure 2) was confirmed, since simulated and experimental evaporator temperatures are nearly identical over the 72-hour period, with the exception of periods with high insolation on January 5 and 7 (Figure 15). This may be a result of the new absorber fin design in which the fins are soldered into each evaporator centerline, thus 
leaving a portion of the evaporator directly exposed to insolation and, accordingly, resulting in slightly higher experimental temperatures than simulated temperatures that only account for $k_{12}$ heat transfer from the absorber. Although the experimental evaporator temperatures are as much as $3.07 \mathrm{~K}$ higher during these times, the remaining experimental and simulated temperatures (during periods of lower insolation) are very close and the average difference in temperatures over the 72-hour period is only $0.5 \mathrm{~K}$.

The matching study conducted by Albanese, et al. [2012], in which simulated temperatures were matched to experimental bench-scale model temperatures, achieved best fit when $k_{23}$ was reduced to $6 \%$ of its baseline value. The best fit for the full-scale prototype was obtained when $k_{23}$ was reduced to $4 \%$. Large changes in $k_{23}$ are necessary to affect the response of the thermal network because the initial value of $k_{23}$ was nearly 35 times larger than all other conductances. With the applied $96 \%$ reduction, the conductance for $k_{23}$ was still 1.4 times larger than the next largest conductance in the network, which was conduction through the thin tank wall, $k_{45}\left(286.8 \mathrm{~W} / \mathrm{m}^{2} \mathrm{~K}\right)$, and 3.8 times larger than the maximum conductance for temperaturedependent convection from the condenser to tank, $k_{34}\left(104.2 \mathrm{~W} / \mathrm{m}^{2} \mathrm{~K}\right)$.

While the conductance between the tank wall and room, $k_{56}$, was based on wellestablished formulas for free convection from a vertical flat surface, radiation affects were unaccounted for. The best fit was obtained when $k_{56}$ was increased by a factor of 2 , while retaining the same temperature-dependent functional form. This implies that radiation is a significant component of $k_{56}$ due to high emissivity of the flat black surface of the tanks and a higher temperature difference between the tank wall and room walls, floor and ceiling (driving radiative heat transfer) than that between the tank wall and adjacent boundary layer (driving convective heat transfer). Additionally, the solar wall conductance $k_{41}$ was increased by a factor 
of 4 to match the rate of decrease in tank temperature during cloudy and/or nighttime periods. This increase was most likely a result of imperfect insulation in the solar wall. However, the increased value of $k_{41}$ remained low at $0.6586 \mathrm{~W} / \mathrm{m}^{2} \mathrm{~K}$. The maximum difference between simulated and experimental tank temperatures over the 72-hour period was $1.45 \mathrm{~K}$ and the average difference was $0.41 \mathrm{~K}$.

Finally, room capacitance was increased by a factor of 4.75 to match the rate of room temperature increases and decreases. With thermal mass of only the room air and OSB sheathing initially added for matching, it was expected that an increase in the thermal mass would be required. Additional room components included 11.25" of EPS core for all walls and the floor, 16 " of EPS core in the roof, $2 \times 12$ connection posts at the end of each panel, a computer desk, and data acquisition hardware. Once the temperature rates in the room were matched, the best fit for the room was obtained at an LCR equal to $8.0 \mathrm{~W} / \mathrm{m}^{2} \mathrm{~K}$. Potential reasons for a higher LCR value than that calculated are infiltration through the door (which was sealed by the blower door apparatus during infiltration measurements) and uncertainty in R-value ratings for envelope components. After matching, the maximum difference between simulated and experimental room temperatures over the 72-hour period was $0.71 \mathrm{~K}$ and the average difference was $0.19 \mathrm{~K}$. 


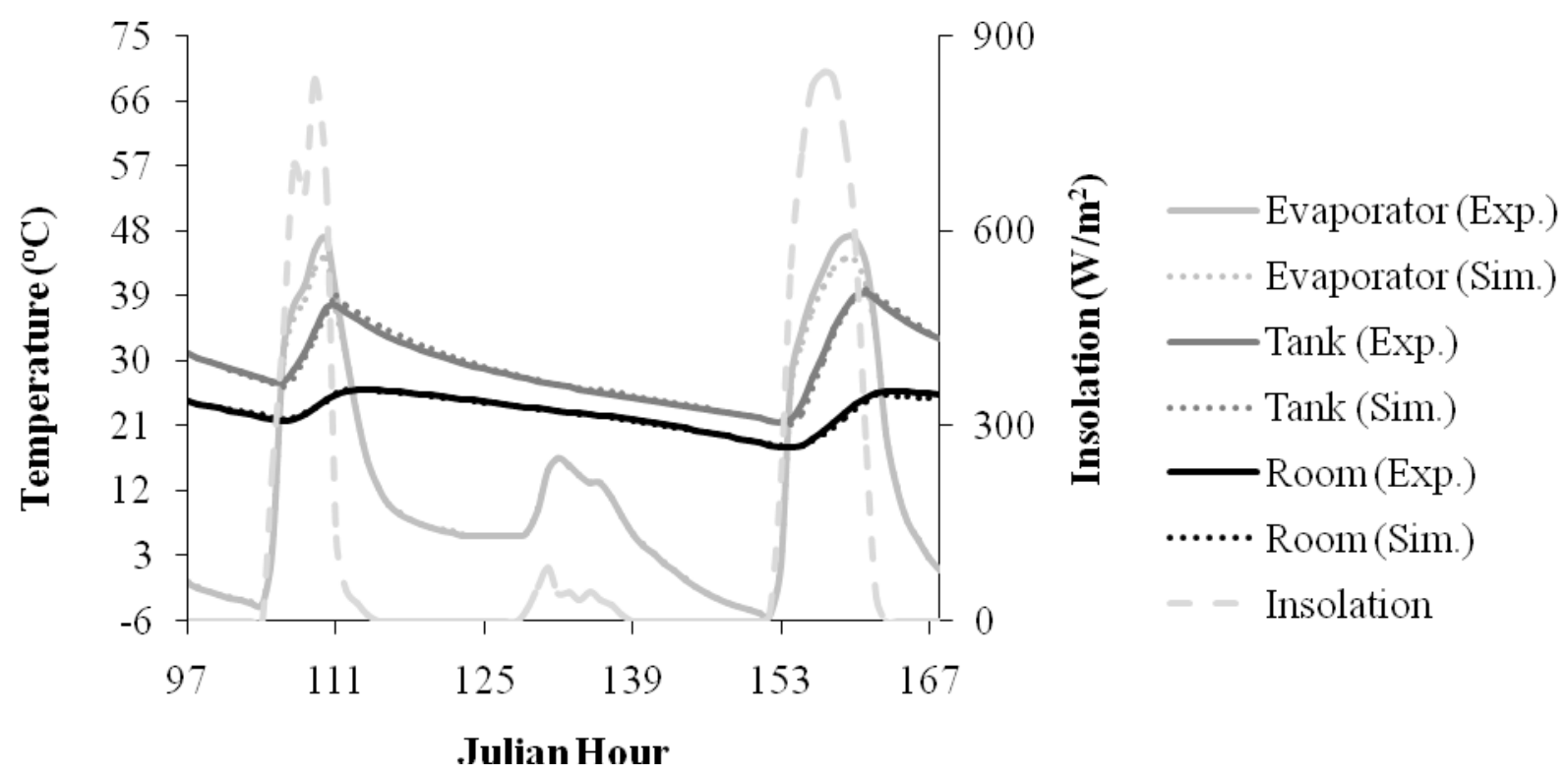

Figure 15. Simulated and experimental evaporator, tank and room temperatures, from January 5-7, after matching.

Table 4. Conductances before and after matching with experiments.

\begin{tabular}{|c|c|c|}
\hline Conductance & $\begin{array}{c}\text { Before Matching } \\
\left(\mathbf{W} / \mathbf{m}^{2} \mathbf{K}\right)\end{array}$ & $\begin{array}{c}\text { After Matching } \\
\left(\mathbf{W} / \mathbf{m}^{2} \mathbf{K}\right)\end{array}$ \\
\hline$k_{23}$ & 9861.1 & 394.4 \\
\hline$k_{56}$ & $5.0 / 6.6$ & $6.4 / 12.5$ \\
\hline$k_{41}$ & 0.1646 & 0.6586 \\
\hline$k_{67}$ & 3.7 & 8.0 \\
\hline Capacitance & $\begin{array}{c}\text { Before Matching } \\
(\mathbf{J} / \mathbf{K})\end{array}$ & $\begin{array}{c}\text { After Matching } \\
(\mathbf{J} / \mathbf{K})\end{array}$ \\
\hline Room & $5.0 \times 10^{5}$ & $2.4 \times 10^{6}$ \\
\hline
\end{tabular}

\section{CONCLUSIONS}

The performance of the solar heat pipe system, previously shown to already have significant thermal performance advantages over other conventional passive systems, has been further enhanced with several key design modifications. These modifications, including a copper absorber, soldered joint between absorber and evaporator, rubber adiabatic section, thicker 
insulation, and one condenser exposed directly to room air, increase the rate of useful gains and reduce thermal losses, leading to greater system efficiency and higher room temperature.

These results also highlight the potential for very high solar fraction in well-insulated buildings, such as the passive solar test facility used in this study. The decrease in load to collector ratio LCR from $10 \mathrm{~W} / \mathrm{m}^{2} \mathrm{~K}$, characteristic of typical buildings, to $3.7 \mathrm{~W} / \mathrm{m}^{2} \mathrm{~K}$, estimated for the PSTF, resulted in a simulated increase in solar fraction from $62.5 \%$ to $89.2 \%$, even in the cool and moderately sunny climate of Louisville, KY. However, a challenge for utilizing low LCR is evident in the elevated room temperatures in Figure 13, indicating the need to vent excess heat during these winter months. While ventilation may be effective during the winter, more problematic is unwanted gains during the spring, fall and summer, when ambient temperature is too high to provide cooling. Thus to effectively utilize low LCR, unwanted thermal gains must be reduced during periods when ambient temperature exceeds the upper comfort limit, for instance by passive and/or active control mechanisms.

After adjustments to conductances between the evaporators and condensers $\left(k_{23}\right)$, between the tank wall and room $\left(k_{45}\right)$, solar wall insulation $\left(k_{41}\right)$, and the LCR $\left(k_{67}\right)$, simulated system temperatures matched well with experimental data. It was also necessary to add additional thermal mass in the room to achieve the best fit. While the capacitances for the evaporators, condensers, and tank wall were negligible with respect to simulation results, it is pertinent to note that since absorber temperatures were fixed using experimental data in the matching study, thermal mass for the absorber was not considered.

A thorough economic analysis has yet to be performed to evaluate tradeoffs between system efficiency and overall cost. An example of a compromise that may reduce the cost per unit of energy saved is the absorber design. While the copper absorber improved system 
efficiency slightly compared the previous aluminum absorber, the greater cost must be taken into account. Similar tradeoffs exist in each component, as well as in the integrated design, for reducing manufacturing, transportation and installation costs.

\section{ACKNOWLEDGEMENT}

This work was supported by DOE grant DE-FC36-05GO85034.

\section{REFERENCES}

Albanese MV, Robinson BS, Brehob EG \& Sharp MK. Simulated and Experimental Performance of a Heat Pipe Assisted Solar Wall. Solar Energy, 86:5:1552-62, 2012.

American Society for Testing Materials (ASTM) International Standard E779: Standard Test Method for Determining Air Leakage Rate for Fan Pressurization. 2010.

Corliss JM. Evaluation of Heat Pipe Application for Passive Solar Systems. DOE Rep., Dept. of Energy, Washington, D.C. 1979.

Dunn, P. D., \& Reay, D. A. (1994). Heat Pipes. Oxford: Pergamon Press.

Incropera, Frank P \& DeWitt, David P. Introduction to Heat Transfer, $\sigma^{\text {th }}$ ed. Hobokenm NJ: Wiley, 2011.

Nkwetta DN, Smyth M, Haghighat F, Zacharopoulas A \& Hyde T. Experimental Performance Evaluation and Comparative Analyses of Heat Pipe and Direct Flow Augmented Solar Collectors. Applied Thermal Engineering, 60:1-2:225-233, 2013.

Ripple D, Burns GW \& Scroger MG. Assessment of uncertainties of thermocouple calibrations at NIST. NISTIR 5340 (Gaithersburg, Maryland, National Institute of Standards and Technology), 1994. 34p.

Robinson BS, Chmielewski NE, Knox Kelecy A, Brehob EG, Sharp MK. Heating season performance of a full-scale heat pipe assisted solar wall. Solar Energy 87:76-83, 2013.

SRCC, 2012. Solar Rating and Certification Corporation. <http:// http://www.solar-rating.org/ ratings/index.html. (ACCESSED 04/05/2014).

Susheela N \& Sharp MK. A Heat Pipe Augmented Passive Solar System for Heating of Buildings. J Energy Eng 127:1:18-36, 2001. 